\title{
Experimental model of congenital toxoplasmosis in guinea-pigs: use of quantitative and qualitative PCR for the study of maternofetal transmission
}

\author{
P. FLORI, J. HAFID*, T. BOURLET, H. RABERIN, C. GENIN and R. TRAN MANH SUNG
}

Groupe Immunité des Muqueuses et Agents Pathogènes (GIMAP), Faculté de Médecine Jacques Lisfranc, 15 rue Ambroise Paré, 42023 Saint Etienne, France and *Unité d'Immunologie et de Physiologie, Département de Biologie, Faculté des Sciences et Techniques, Avenue A. El Khattabi, BP 618, 40000 Marrakech, Morocco

\begin{abstract}
Maternofetal transmission of Toxoplasma gondii was assessed in pregnant guinea-pigs, with a gestational period of $65 \pm 5$ days. A total of 56 female guinea pigs was infected by the intraperitoneal route (RH strain), by the oral or the intraperitoneal route (Prugniaud strain; PRU) or by the oral route (76K strain). Inoculation was performed $90 \pm 18$ days or $30 \pm 9$ days before the onset of gestation or $20 \pm 6$ days or $40 \pm 6$ days after. Gestational age was determined by a progesterone assay. Parasite loads (fetal brain and liver) were assessed by nested PCR and real-time PCR quantification on Light Cycler $^{\circledR}$ was performed with a SYBR Green $I^{\circledR}$ technique. The $76 \mathrm{~K}$ strain appeared to be the most virulent in the model: the neonatal survival rate was $31 \%$, in contrast to $53 \%$ and $68 \%$ for the PRU and RH strains, respectively. The percentage of survival of neonates for all strains taken together was lower after inoculation at 40 days' gestation (25\%) than at 20 days' gestation (77\%). Whatever the strain, maternofetal transmission determination was greater with nested PCR (54\% for RH, 84\% for PRU and $86 \%$ for $76 \mathrm{~K}$ strains) than with real-time quantitative PCR (31\% for RH, $66 \%$ for PRU and $76 \%$ for $76 \mathrm{~K}$ strains). However, real-time quantitative PCR showed that neonatal parasite load was greater with the cystogenic strains (76K, PRU) and that high hepatic load (>10000 parasites/g) was often associated with disease severity (11 of 12 cases). Therefore, this technique may provide an important element in understanding this congenital disease.
\end{abstract}

\section{Introduction}

Toxoplasmosis, caused by Toxoplasma gondii, is widespread in man and warm-blooded animals. Although usually asymptomatic in immunocompetent individuals, toxoplasmosis may cause severe disorders in immunocompromised patients and in pregnant women because of the high risk of transplacental transmission and the occurrence of multiple congenital lesions in the fetus $[1,2]$. Physiological, immunological and therapeutic knowledge of maternofetal transmission is limited because experimental models are few [3]. Several models of congenital toxoplasmosis in rodents such as mouse, rat, guinea-pig and rabbit (few studies) have been described [4]. The mouse is the oldest and best

Received 14 Dec. 2001; revised version received 3 April 2002; accepted 4 April 2002.

Corresponding author: Dr P. Flori (e-mail: pierre.flori@, univ-st-etienne.fr). studied experimental model of congenital toxoplasmosis [5-7]. In most cases, mice are very sensitive to $T$. gondii infection and fetal contamination could occur during chronic maternal toxoplasmosis and even through successive generations of mice $[6,8]$. In contrast, the rat model has been only described more recently. Its main advantage lies in the fact that rats, like man and other primates, are resistant to $T$. gondii infection. Reported maternofetal transmission varies according to study, route, load, time of inoculation and strain of T. gondii [9-11]. Fetuses are hardly ever seriously ill and little or no fetal transmission occurs during chronic maternal toxoplasmosis [11-13]. Halfway between the rat and mouse model, the guinea-pig model of $T$. gondii infection shows several features relevant to the study of congenital toxoplasmosis: (i) as in man, the placenta is haemomonochorial [4]; (ii) the duration of gestation is 65 days (45 days longer than in rat and mouse models) $[8-10,14]$; (iii) the sensitivity of guinea-pigs to T. gondii is medium. However, studies 
in pregnant guinea-pigs are mostly outdated [14-16]. Only one recent vaccine study has used this model, but does not completely describe it [17]. Basically, the older experiments consisted of challenging the mother during pregnancy and assessing the fetal transmission rate either by direct observation or, more often, by subinoculation of mice with fetus homogenates. The present study describes the development of a model of guinea-pig congenital toxoplasmosis with molecular techniques. These technologies (nested PCR and realtime quantitative PCR) are very sensitive [18-20] and can be adapted for extensive study.

\section{Materials and methods}

\section{Animals and parasites}

Female and male Dunkin Hartley guinea-pigs were purchased from Harlan (Gannat, France). Fifty-six female guinea-pigs weighing $600-800 \mathrm{~g}$ were transferred to our animal facilities. Their sera were obtained by intracardiac puncture and the absence of Toxoplas$m a$ antibodies was verified by indirect immunofluorescence antibody test (IFAT).

Three strains of $T$. gondii were used: the highly virulent RH strain, the mildly virulent $76 \mathrm{~K}$ strain and the slightly virulent Prugniaud (PRU) strain as previously used by Zenner et al. [10]. The RH strain (tachyzoite form) was maintained through successive intraperitoneal tachyzoite passages in mice every 3 days as described previously [21]. Briefly, tachyzoites obtained from ascitic fluid of OF1 mice (Charles River, L'Arbresle, France) infected 3 days earlier were used for intraperitoneal infection after counting and dilution as necessary $\left(10^{5}-10^{6}\right.$ factor dilution). The $76 \mathrm{~K}$ and
PRU strains (cystogenic strains) were maintained by oral inoculation of cysts in mice every 3 months as described previously [22]. Briefly, cysts obtained from the brains of OF1 mice infected 3 months earlier were used for oral or intraperitoneal infection. Under sterile conditions, brains from infected mice were homogenised in a $20-\mathrm{ml}$ potter's tube, and the cysts were counted and diluted as necessary (5-20 factor dilution).

\section{Mating and infection of female guinea-pigs}

Groups of three, five or seven female guinea-pigs were kept in separate cages with one or two males for mating. After the 18th day of the menstrual cycle, the female guinea-pigs were housed in individual cages and grouped according to the time, strain and route of inoculation. On day 20 or 27 after the beginning of mating, two serum progesterone $(\mathrm{Pg})$ measurements (Access ${ }^{\circledR}$ Beckman-Coulter, Villepinte, France) were performed to confirm and date the gestational age [23].

In all, 32 animals were infected by the intraperitoneal route (IP) with 100 tachyzoites of the RH or 100 cysts of the PRU strains. Another 24 animals were infected by the oral route $(\mathrm{OR})$ with 100 cysts of the $76 \mathrm{~K}$ or PRU strains. Animals were infected by the IP or OR before or after the beginning of gestation as follows: six guinea-pigs on the 90th day (G-90 \pm 18 days) and six guinea-pigs on the 30th day (G-30 \pm 9 days) before the beginning of gestation; 22 guinea-pigs on the 20th day (G20 \pm 6 days) and 22 guinea-pigs on the 40th day ( $\mathrm{G} 40 \pm 6$ days) after the beginning of gestation (Table 1). To confirm infection, $T$. gondii IFAT was performed on the 14th and the 30th days after inoculation.

Table 1. Experimental congenital toxoplasmosis in female guinea-pigs inoculated with different strains of T. gondii 30 (G-30) or 90 (G-90) days before pregnancy and $20(\mathrm{G} 20)$ and 40 (G40) days after the beginning of pregnancy

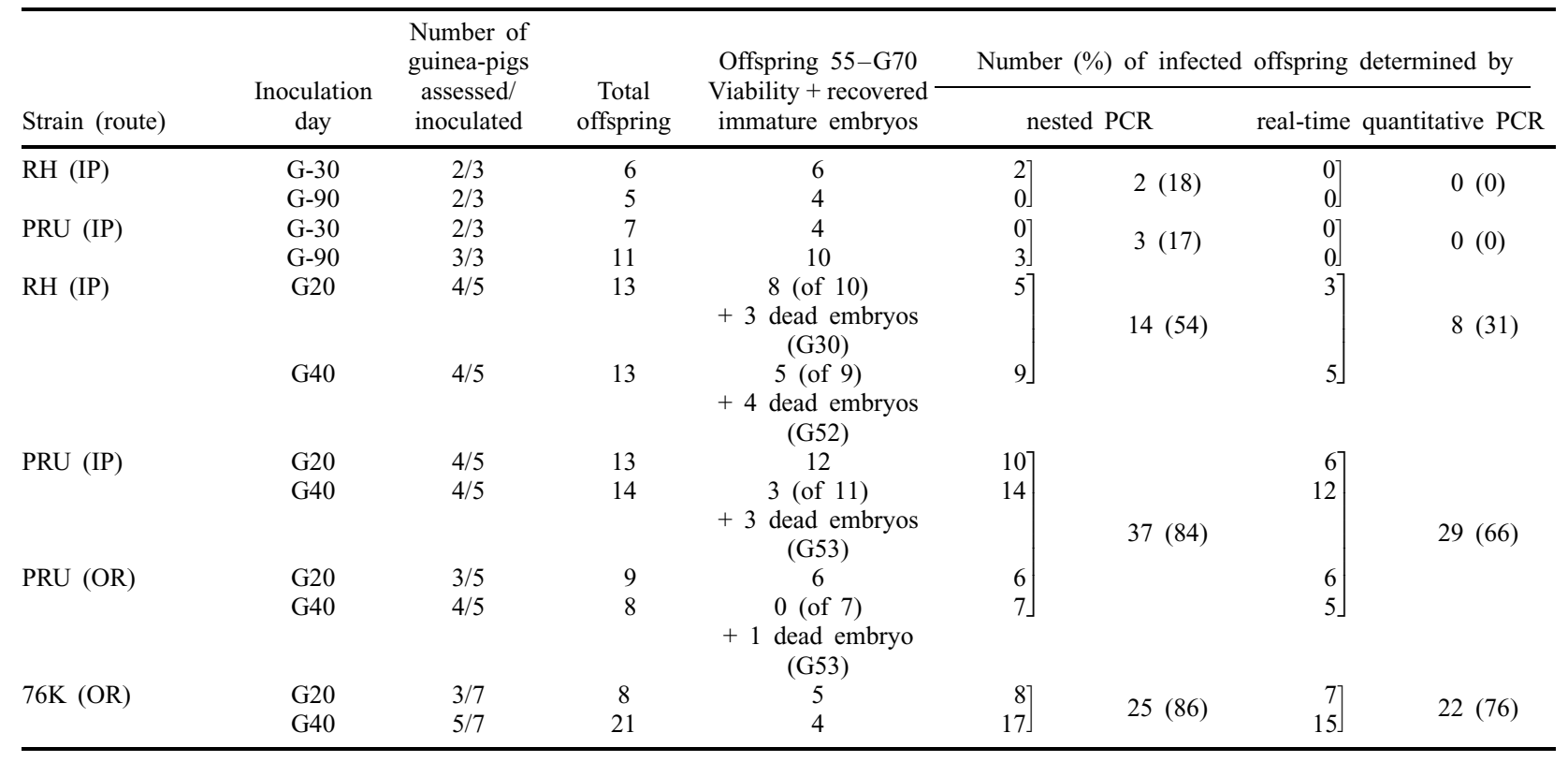

OR, oral route; IP, intraperitoneal route; G55-G70 offspring, offspring of gestational age 55-70 days. 


\section{Organ harvesting of newborn guinea-pigs}

A large number of newborn guinea-pigs were either stillborn (SB) or non-viable (NV), perhaps because of the congenital toxoplasmosis. The other newborns were killed with phenobarbital 15 days after birth. Stillborns were thoroughly washed with distilled water to avoid possible contamination with circulating parasites from maternal blood and amniotic fluid. Liver and brain were removed separately with sterile instruments, washed in phosphate-buffered saline (PBS), wiped and weighed and then parts of the organs were placed in 1.5-ml Eppendorf tubes. They were homogenised and ground with a pestle in the Eppendorf tube.

\section{Nested PCR and real-time quantitative PCR}

Extraction and purification. To detect T. gondii DNA in the organ homogenate, $50 \mu \mathrm{g}$ of brain or liver were used for DNA extraction with the High Pure PCR Template Preparation $\mathrm{Kit}^{\circledR}$ (Roche Molecular Biochemicals, Meylan, France) according to manufacturer's recommendations. Briefly, after homogenisation and grinding with the pestle for the Eppendorf tube (sterile, DNA-free material for single use), cells were lysed by a short incubation with proteinase $\mathrm{K}$ (included in the kit) in the presence of a chaotropic salt (guanidine-HCl). Cellular DNA binds selectively to special glass fibres pre-packed in the High Pure Purification filter tube. Bound DNA was purified in a series of rapid 'wash-and-spin' steps to remove contaminating cellular components. Finally, $200 \mu \mathrm{l}$ of low salt elution fluid (included in the kit) released the DNA from the glass fibre. The concentration was determined to be $100-300 \mathrm{mg} / \mathrm{L}(100-200 \mathrm{mg} / \mathrm{L}$ for brain and $150-300 \mathrm{mg} / \mathrm{L}$ for liver extracts). Purity of DNA was measured by UV spectrophotometry $\left(\mathrm{OD}_{260} /\right.$ $\mathrm{OD}_{280}$ between 1.6 and 1.8).

Nested PCR. Nested PCR was performed in a final volume of $50 \mu \mathrm{l}$ containing $10 \mathrm{pmol}$ of each primer, $200 \mu \mathrm{M}$ deoxynucleoside triphosphates (dATP, dCTP, dGTP, dUTP $\times 2$; Roche), $50 \mathrm{mM} \mathrm{MgCl}_{2}$ (Life Technologies, Cergy Pontoise, France) $3 \mu \mathrm{l}$, PCR buffer $10 \times(200 \mathrm{~mm}$ Tris-HCl, $500 \mathrm{~mm} \mathrm{Kcl}, \mathrm{pH} 8.3$ (Life Technologies) $5 \mu \mathrm{l}$, Taq DNA polymerase (Life Technologies) $1.25 \mathrm{U}$ and $4 \mu \mathrm{l}$ of purified DNA. The denaturing, annealing and extension times were $1 \mathrm{~min}$ each at $95^{\circ} \mathrm{C}, 58^{\circ} \mathrm{C}$ and $72^{\circ} \mathrm{C}$, respectively. The final extension step continued for a further $10 \mathrm{~min}$. In the first round, DNA samples were amplified for 40 cycles with 5'-GGAACTGCATCCGTTCATGAG-3' and 5'TCTTTAAAGCGTTCGTGGTC-3' primers derived from the T. gondii B1 gene [24] to produce a 194-bp fragment. In the second round, a $1-\mu 1$ portion of the first amplification product was amplified for only 25 cycles, under the same conditions as in the first round but with $5^{\prime}$-TGCATAGGTTGCAGTCACTG-3' and 5'GGCGACCAATCTGCGAATACACC-3' primers [24] to produce a 97-bp internal fragment. The products were separated on agarose (Metaphor ${ }^{\mathbb{R}}$ agarose, Tebu)
$3 \%$ and detected after staining with ethidium bromide under UV illumination.

Development of real-time quantitative PCR. PCR was performed with the LC FastStart DNA Master SYBR Green I ${ }^{\mathbb{B}}$ (Roche) in a standard PCR reaction containing $0.4 \mu \mathrm{m}$ of each selected primer 5'-TGAAGAGAGGAAACAGGTGGTCG-3' and 5'-CCGCCTCCTTCG TCCGTCGTA-3' [25] derived from the $T$. gondii B1 gene, $3 \mathrm{mM} \mathrm{MgCl}_{2}$ and precisely $50 \mathrm{ng}$ of genomic DNA in $4 \mu \mathrm{l}$ of sample dilution. To prevent potential carry-over contamination of the amplified target DNA from previous reactions, the PCR reaction mix was incubated initially with uracyl-DNA-glycosilase (Roche) for $5 \mathrm{~min}$ at room temperature. Amplification and detection were performed in a LightCycler ${ }^{\mathbb{R}}$ instrument $^{\mathbb{B}}$ (Roche) as follows: $20 \mu \mathrm{l}$ of reaction mixture were incubated initially for $10 \mathrm{~min}$ at $95^{\circ} \mathrm{C}$ to denature the DNA and activate the Fast Start Taq DNA; amplification was performed for 40 cycles of denaturation $\left(95^{\circ} \mathrm{C}, 15 \mathrm{~s}\right.$, ramp rate $\left.20^{\circ} \mathrm{C} / \mathrm{s}\right)$, annealing $\left(68^{\circ} \mathrm{C}\right.$, $4 \mathrm{~s}$, ramp rate $\left.20^{\circ} \mathrm{C} / \mathrm{s}\right)$ and extension $\left(72^{\circ} \mathrm{C}, 8 \mathrm{~s}\right.$, ramp rate $\left.20^{\circ} \mathrm{C} / \mathrm{s}\right)$. A single fluorescence reading for each sample was taken at the extension step. Quantitative results were expressed by determination of the detection threshold or the crossing point $(\mathrm{Cp})$, which marked the cycle when the fluorescence of the given sample significantly exceeded the baseline signal. They were expressed as a fractional cycle number. Then, the Cps were plotted against the known parasite concentration to obtain a standard curve. The parasite count for a given tissue sample was calculated by extrapolation from this standard curve. Positive sample specificity was confirmed by determining the melting curve $\left(95^{\circ} \mathrm{C}\right.$, $0 \mathrm{~s}$, ramp rate $20^{\circ} \mathrm{C} / \mathrm{s} ; 68^{\circ} \mathrm{C}, 15 \mathrm{~s}$, ramp rate $20^{\circ} \mathrm{C} / \mathrm{s}$; $95^{\circ} \mathrm{C}, 0 \mathrm{~s}$, ramp rate $0.1^{\circ} \mathrm{C} / \mathrm{s}$, continuous measurement). The melting point of the specific amplification product (131 bp) was $84 \pm 0.5^{\circ} \mathrm{C}$.

To obtain standard ranges for nested PCR and real-time quantitative PCR assays, the trophozoites of strain RH from mouse peritoneal fluid were quantified with Nageotte cells. The DNA of the control was extracted under the same condititions and then a series of 10-fold dilutions were made. Different negative extracts (from liver or brain) were loaded with known dilutions and this series (equivalent extract tissue) was included in each amplification run (Fig. 1).

\section{Statistical analysis}

Statistical assessment of differences in mean viability and maternofetal transmission was done by the $\chi^{2}$ test ( $p<0.05$ was considered significant).

\section{Results}

Follow-up of female guinea-pigs

Only 45 of the 56 guinea-pigs could be included in the 
a

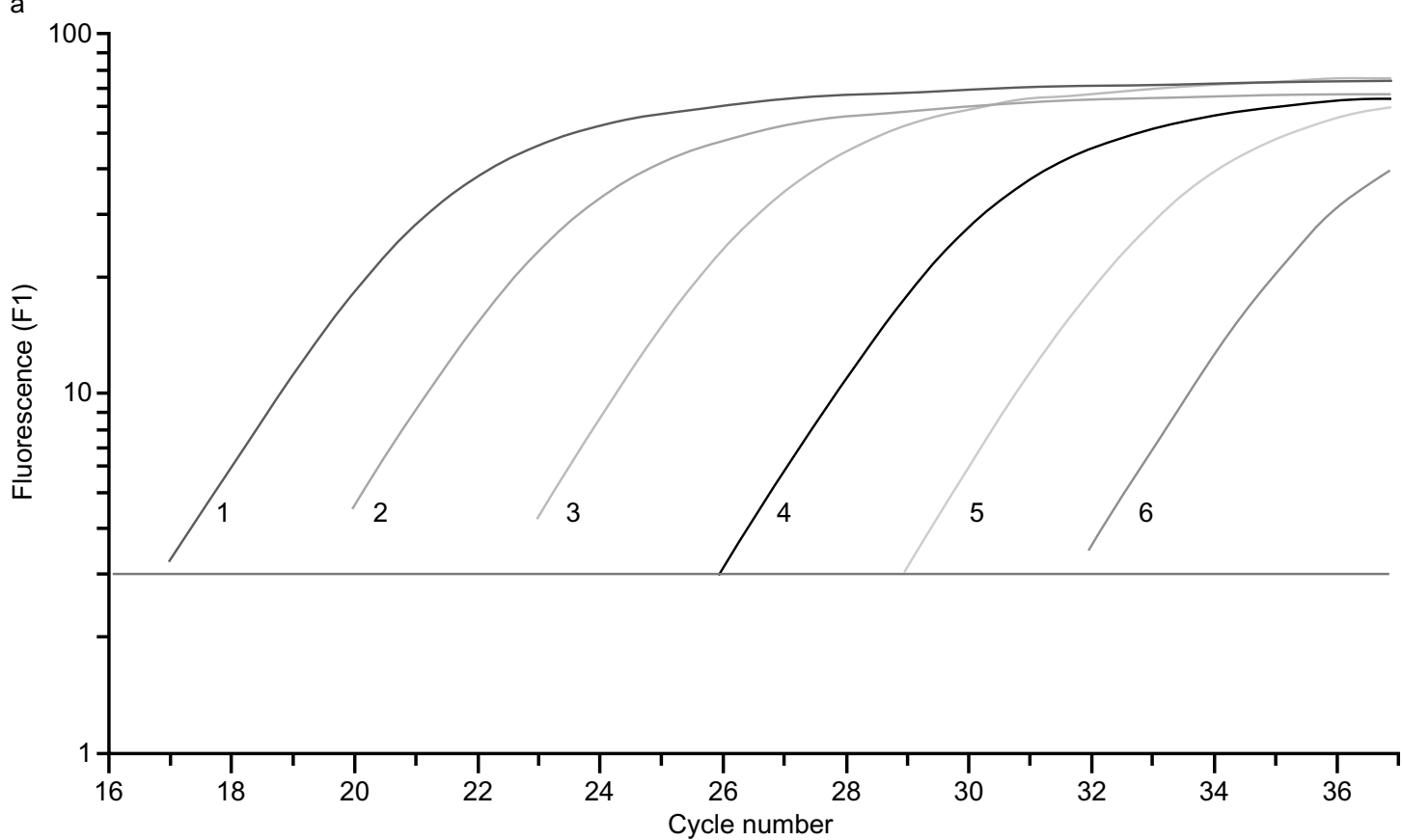

b

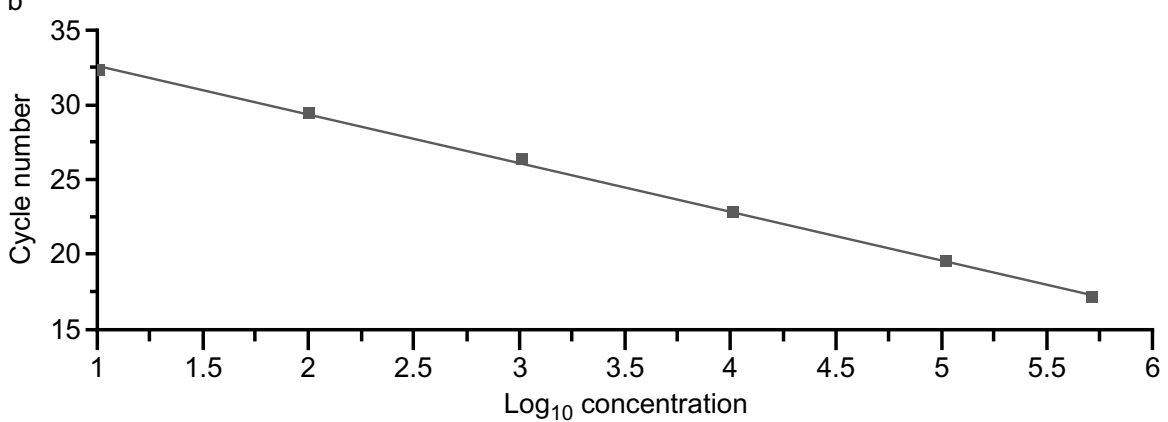

Fig. 1. (a) Real-time quantitative LC-PCR test with SYBR Green $\mathrm{I}^{\circledR}$. Amplification plots obtained for T. gondii DNA from $5 \times 10^{5}$, and serial 10 -fold dilutions from $10^{5}$ to 10 parasites in extract. Each slope corresponds to a particular input target quantity: 1, from $5 \times 10^{5}$ parasites/extract; $2,10^{5}$ parasites/extract; $3,10^{4}$ parasites/extract; $4,10^{3}$ parasites/extract; $\mathbf{5}$, $10^{2}$ parasites/extract; 6, $10^{1}$ parasites/extract. (b) Plot of crossing points against the input target quantity (common log scale) showing the linearity of the results. The computer-calculated correlation coefficient (r) is 1 , the variations coefficient is $26.7 \%$ $($ error $=0.267)$; slope $=-3.204$; intercept $=35.28$.

protocol; the other 11 were not gestating (6) (Pg concentration $<10 \mathrm{ng} / \mathrm{ml}$ on two samples), not infected (3) (inoculation not leading to seroconversion) or dead (2) secondary to intracardiac puncture.

Of the 45 guinea-pigs, 6 aborted early (gestation $<35$ days) and offspring could not be counted except for one. Thus, 40 guinea-pigs remained, with 128 fetuses or neonates (number of neonates per litter $=3.2 \mathrm{SD}$ 0.97) from which 249 samples (121 brain and 125 liver samples from neonates or fetuses $\geqslant 35$ days and 3 fetal samples from the fetuses aborted at $<35$ days) were taken and analysed.

\section{Offspring viability according to strain and time of inoculation}

For inoculation during gestation, percentage viability of offspring at a gestational age of 55-70 days was $68 \%$
(13/19) for strain RH, 53\% (21/40) for PRU and 31\% $(9 / 29)$ for $76 \mathrm{~K}$. Thus the number of viable offspring was significantly lower with strain $76 \mathrm{~K}$ than with the other strains $\left(\chi^{2}\right.$ test, $\left.\mathrm{p}=0.019\right)$. It was also found that early abortions were more frequent after G20 inoculation with $76 \mathrm{~K}$ (4/7 gestating females) than with PRU and RH strains (2/12 gestating females).

Inoculation was done at 20 days or 40 days after onset of gestation (G20 and G40, respectively). Percentage viability of offspring at gestational age $>55$ days (all strains taken together) was $77 \%(31 / 40)$ for $\mathrm{G} 20$, but only $25 \%(12 / 48)$ for G40 ( $\chi^{2}$ test, $\left.p<0.001\right)$. However, this difference in viability was less marked with strain RH than with the cystogenic PRU and $76 \mathrm{~K}$ strains (Table 1).

There was also a small number of pre-gestational inoculations (on G-90 days and G-30 days); in these 
cases offspring viability remained high at $83 \%(24 / 29)$ and this percentage was similar to those of the G20 post-gestation inoculations (77\%).

Two different inoculation routes were tested (IP and OR) only for strain PRU and no significant difference in offspring viability was found $\left(\chi^{2}\right.$ test, $\left.p=0.19\right)$.

\section{Development of real-time quantitative PCR}

Fig. 1 shows the amplification of the purified T. gondii DNA in 10-fold serial dilutions with fluorescence plotted against cycle number. The higher the initial copy number, the earlier the fluorescent signal appears. The sensitivity of the system is such that as few as two parasites/extract can be distinguished from the background signal. However, because of the dilution required by the assay ( 1 in 10 or 1 in 20 ) to avoid an excess of non-specific DNA, the sensitivity of the assay was $20-40$ parasites $/ 50 \mu \mathrm{g}$ of tissue. The intraassay variation coefficient was $5 \%$ (high concentration $\mathrm{DNA}=1800$ parasites) and $24 \%$ (low concentration $\mathrm{DNA}=25$ parasites). The inter-assay variation coefficients were $73 \%, 35 \%, 24 \%$ and $21 \%$ for samples with $10,25,110$ and 1800 parasites, respectively.

\section{Comparison of sensitivity between different PCR techniques}

Nested PCR sensitivity was 1-2 parasites/50 $\mu \mathrm{g}$ of tissue. Sensitivity of quantitative PCR was 20-40 parasites $/ 50 \mu \mathrm{g}$ of tissue because of the dilution necessary in the assay. Comparative sensitivities of these techniques for the 249 tissue extracts are shown in Table 2. Only the nested PCR was positive in 33 samples in contrast to three samples positive only by the real-time quantitative PCR, confirming the better sensitivity of the former technique. The 36 discordant samples were tested in the second series and the first results were confirmed.

\section{Parasite load according to strain, time of inoculation and type of tissue}

An offspring was deemed to be affected when there was at least one (liver or brain) positive test. With nested PCR, percentage maternofetal transmission was lower with strain RH (54\%) than with 76K (86\%) and PRU $(84 \%) \quad\left(\chi^{2}\right.$ test, $\left.p=0.001\right)$. With real-time

Table 2. Comparison of sensitivity of LightCycler ${ }^{\circledR}$ real-time quantitative PCR and nested PCR of 249 extracts of tissue (brain and liver) from guinea-pig offspring infected with different strains of $T$. gondii

\begin{tabular}{lccc}
\hline & \multicolumn{3}{c}{ LightCycler $^{\circledR}$ PCR result } \\
\cline { 2 - 4 } Nested PCR result & Negative & Positive & Total \\
\hline Negative & 128 & 3 & 131 \\
Positive & 33 & 85 & 118 \\
Total & 161 & 88 & 249 \\
\hline
\end{tabular}

quantitative PCR, regardless of the strain, percentage of maternofetal transmission was lower - 31\%, 76\% and $66 \%$, respectively (Table 1). Moreover, whatever organ and route was analysed, the mean positive parasite load after inoculation with RH $(\mu=2240$ SD 1920 parasites/g) was lower than with the cystogenic strains (PRU, $\mu_{1}=5840$ SD 6090 parasites $/ g$; $76 \mathrm{~K} \mu_{2}=10900 \mathrm{SD} 13340$ parasites/g) (Fig. 2).

Percentage maternofetal transmission rates were significantly lower $(19$ and $15 \%)\left(\chi^{2}\right.$ test, $\left.p<0.001\right)$ when inoculations had been carried out before the onset of gestation (G-90, G-30) than in those inoculated after (67\% for G20, $84 \%$ for G40). The mean tissue loads showed the same pattern: for all the G-90 and G-30 inoculated offspring tissue loads were unquantifiable $(<400$ parasites/g), whereas loads after G20 and G40 inoculations were much greater (6880 SD $10 \quad 100$ parasites/g).

The qualitative and quantitative analyses of the tissue load were done by comparing the tissue samples from liver with those from the brain. No significant difference was found either in the percentage of samples positive with the nested PCR $50 \%$ for liver versus $48 \%$ for brain samples) or in the mean load (9160 SD 13040 parasites/g for liver versus $6380 \mathrm{SD}$ 9000 parasites/g for brain samples). However, there was a significant difference in the association of high hepatic load (>10000 parasites/g) and offspring viability. Whatever the date of inoculation and the strain, 11 of 12 offspring with high hepatic loads were stillborn, whereas only 2 of 9 offspring with high brain loads were stillborn (Fig. 2).

\section{Discussion}

The guinea-pig model has been described in various studies [14-17, 26]. Halfway between the rat and mouse, guinea-pig sensitivity to $T$. gondii is medium. Adult animals may die with infection with an inoculum of $\geqslant 1000$ tachyzoites of strain RH $[15,26]$, whereas they remain insensitive with the semi-virulent or weakly virulent strains. Nevertheless, whatever the strain of $T$. gondii, fetuses were often seriously ill [14, 26 and present study], an observation not seen in rats. Guinea-pig placenta has a composition close to that of human (i.e., haemomonochorial), suggestive of similar modes of transmission. Hormonal control is cyclic (18 days) and gestation duration is 65 days, long enough to enable comparative studies with different inoculation times (e.g., G20 and G40, in the present study) and comparative chemotherapy studies (satisfactory medicinal impregnation). These reasons formed the rationale for the present study. Therefore the inoculum was adapted to induce a subclinical infection in the female guinea-pigs and the maternofetal transmission in the absence of acute non-controlled maternal infection was studied. The small (100 tachyzoites) inoculum used 

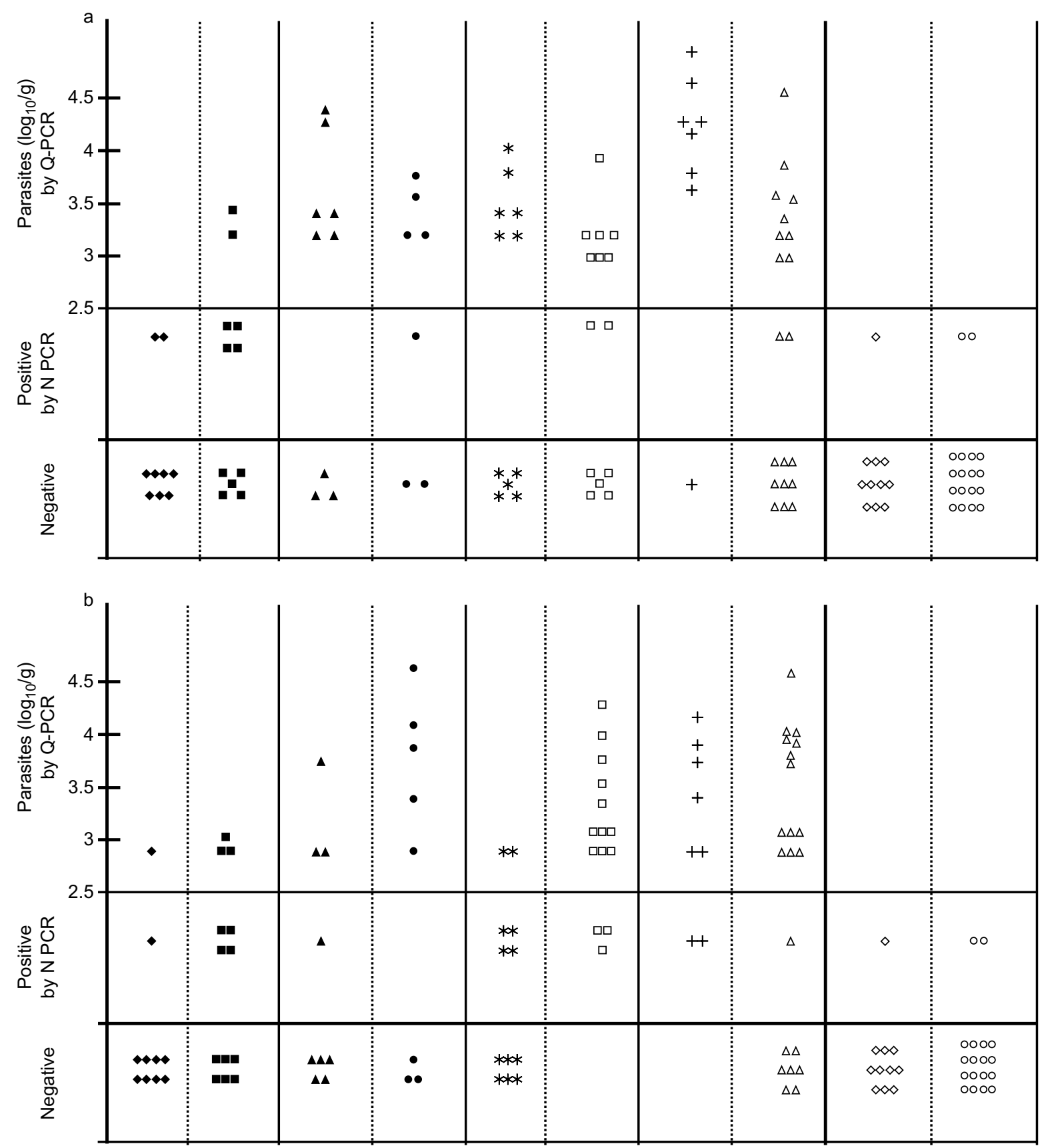

Fig. 2. Parasitic load in brain (a) and liver (b) of guinea-pig offspring from female infected after (G20, G40) and before (G-30, G90) the beginning of the pregnancy. The inoculation was done by oral route (OR) and intraperitoneal route (IP) with RH, Prugniaud (PRU) and 76K strains of T. gondii. G, date of inoculation; $\bullet$, RH, G20, IP; $\boldsymbol{\bullet}$, RH, G40, IP; $\boldsymbol{\Delta}$, PRU, G20, OR; •, PRU, G40, OR; *PRU, G20, IP; $\square$, PRU, G40, IP; +, 76K, G20, OR; $\triangle$, 76K, G40, OR; $\diamond$, RH, G-30-90, IP; ○, PRU, G-30-90, IP.

with strain $\mathrm{RH}$ may account for the low rate of maternofetal transmission (54\% versus $86 \%$ and $84 \%$ with strains $76 \mathrm{~K}$ and PRU, respectively). Nevertheless, it should be borne in mind that a virulent strain (defined in terms of virulence in adult mice) is not necessarily more liable or able to cross the placenta to induce a higher maternofetal transmission rate $[10,11]$.

The present study used the same strains as a previous study involving gestating rats [10], which found maternofetal transmission rates of 58\% (strain RH), $35 \%(76 \mathrm{~K})$ and $63 \%$ (PRU). The results are obviously not directly comparable, yet it is noteworthy that the guinea-pig model was found to be more sensitive to strain $76 \mathrm{~K}$ in the present study, with not only a higher rate of congenital toxoplasmosis but also greater incidence of stillbirth and early abortion.

Comparison of the results of the present study with those from other works (with the guinea-pig model) shows four common features: (i) the percentage of stillborn (SB) and non-viable (NV) fetuses remains high even with inoculation in the second part of gestation (G40): 31 (57\%) SB/54 and 6 (11\%) NV/54 in the present study versus $23(55 \%) \mathrm{SB} / 42$ and 9 (21\%) NV/42 found by Giraud et al. [26]; (ii) after 
inoculation in the first part of gestation (G20), more offspring reaching term were viable and normal $(\mathrm{N}): 31$ (77\%) N/40 in the present study versus $3(100 \%) \mathrm{N} / 3$ found by Giraud et al. [26]; (iii) after pre-gestation inoculation, maternofetal transmission is low: $5(17 \%)$ of 29 in the present study compared with $5(29 \%)$ of 17 for Wright [14]; (iv) abortion, when it occurs, does so between the 8th and the 20th day after inoculation of the mother, as described by these authors $[14,26]$.

In this study, molecular biology techniques were used because they are more sensitive and rapid than other techniques (cell culture, mouse inoculation, capture ELISA, immunoblotting) [27, 28]. For determining parasite load, it was necessary to use the following two techniques: nested PCR and a quantitative PCR. Nested PCR has a sensitivity of detecting $<1$ parasite/ml of amniotic fluid [29], making it the most sensitive of the techniques. In this study, the sensitivity was 1-2 parasites $/ 50 \mu \mathrm{g}$ of tissue. With the single PCR, a decrease in sensitivity of $>10$ parasites was observed because of the presence of excess leucocyte or tissue DNA [30]. The Light-Cycler ${ }^{\circledR}$ quantitative PCR technique is best used only to assess tissue parasite load, because of the reduced sensitivity (20-40 parasites/ $50 \mu \mathrm{g}$ of tissue) resulting from the dilution factor involved in the SYBR Green $I^{\circledR}$ protocol. However, LightCycler ${ }^{\circledR}$ PCR enabled the differential quantification of the tissue load from that in the circulation. Indeed, in another study (data not shown), only 25 parasites/ml were detected (no dilution needed, circulating DNA level low). Very high sensitivity in determining tissue load is not necessarily an advantage as mentioned by Zenner et al. [31]; however, it is essential for detecting circulatory or amniotic fluid loads which, in human subjects reach no more than a few parasites/ml $[19,32]$.

The following points are notable with respect to the quantitative parasite load analysis: (i) there were greater parasite loads with cystogenic strains; (ii) a strong relation was shown between lethal infection and high offspring liver load, probably reflecting generalised systemic infection; and (iii) the absence of any relationship between offspring viability and high brain loads, which were even more frequent in viable offspring, proving that they develop gradually during the latter part of gestation and in the first days after birth. This finding has already been reported $[31,33]$ in kinetic studies of tissue load, although only in mice and adult rats.

In conclusion, after 30 years of silence regarding the guinea-pig model, we believe that the present results are relevant. Transmission rates were $>50 \%$ regardless of the strain used. Moreover, this model has some similarities to congenital toxoplasmosis in man (haemomonochorial placenta, partial transmission, variable severity) and some differences too (congenital transmission during chronic maternal toxoplasmosis, high transmission rates regardless of the time of inoculation during the gestation). Offspring death was frequently associated with high liver load, indicating an uncontrolled systemic infection. Quantitative PCR determination of parasite load may prove to be an important element in the understanding of this congenital disease. Moreover, it could provide an experimental basis for physiopathological, kinetic, therapeutic and vaccine studies.

We thank Lionel Zenner and Karine Kaiser for helpful advice and discussions and Marie Laure Darde for providing T. gondii $76 \mathrm{~K}$ strain. We also acknowledge Yves Boyer and Michel Massa for the animal facility and production of the parasites, Bahrie Bellete for helping to edit the manuscript and the staff of the Laboratory of Parasitology for skilful technical assistance.

\section{References}

1. Desmonts G, Couvreur J. Congenital toxoplasmosis: a prospective study of 378 pregnancies. N Engl J Med 1974; 290: $1110-1116$.

2. Foulon W, Villena I, Stray-Petersen B et al. Treatment of toxoplasmosis during pregnancy: a multicenter study of impact on fetal transmission and children's sequelae at age 1 year. $\mathrm{Am}$ J Obstet Gynecol 1999; 180: 410-415.

3. Derouin F, Lacroix C, Sumyuen MH, Romand S, Garin YJF. Experimental models of toxoplasmosis: pharmacological applications. Parasite 1995; 2: 243-256.

4. Darcy F, Zenner L. Experimental models of toxoplasmosis. Res Immunol 1993; 144: 16-23.

5. Eichenwald H. Experimental toxoplasmosis. 1. Transmission of the infection in utero and through the milk of lactating female mice. Am J Dis Child 1948; 76: 307-315.

6. Beverley JKA. Congenital transmission of toxoplasmosis through successive generations of mice. Nature 1959; 183: $1348-1349$.

7. Remington JS, Jacobs L, Melton ML. Congenital transmission of toxoplasmosis from mother animals with acute and chronic infections. J Infect Dis 1961; 108: 163-173.

8. Roberts CW, Alexander J. Studies on a murine model of congenital toxoplasmosis: vertical disease transmission only occurs in BALB/c mice infected for the first time during pregnancy. Parasitology 1992; 104: 19-23.

9. Dubey JP, Shen SK. Rat model of congenital toxoplasmosis. Infect Immun 1991; 59: 3301-3302.

10. Zenner L, Darcy F, Cesbron-Deslauw M-F, Capron A. Rat model of congenital toxoplasmosis: rate of transmission of three Toxoplasma gondii strains to fetuses and protective effect of a chronic infection. Infect Immun 1993; 61: 360-363.

11. Paulino JP, Vitor RWA. Experimental congenital toxoplasmosis in Wistar and Holtzman rats. Parasite 1999; 6: 63-66.

12. Dubey JP, Shen SK, Kwok OCH, Thulliez P. Toxoplasmosis in rats [Rattus norvegicus]: congenital transmission to first and second generation offspring and isolation of Toxoplasma gondii from seronegative rats. Parasitology 1997; 115: 9-14.

13. Freyre A, Falcón J, Correa O, El Elhou S, Mendez J, Gedda C. Congenital transmission of experimental chronic toxoplasmosis in rats. J Parasitol 1999; 85: 746-748.

14. Wright I. Transmission of Toxoplasma gondii across the guinea-pig placenta. Lab Anim 1972; 6: 169-180.

15. Bérard-Badier M, Laugier M, Louchet E, Payan H. Le placenta dans la toxoplasmose congénitale aiguë expérimentale du cobaye. [The placenta in experimental acute congenital toxoplasmosis in guinea pigs.] Pathol Biol 1968; 16: 829-835.

16. Huldt G. Experimental toxoplasmosis transplacental transmission in guinea pigs. Acta Pathol 1960; 49: 176-188.

17. Haumont M, Dehlaye L, Garcia L et al. Protective immunity against congenital toxoplasmosis with recombinant SAG1 protein in the guinea pig model. Infect Immun 2000; 68: 4948-4953.

18. Jauregui LH, Higgins J, Zarlenga D, Dubey JP, Lunney JK. Development of a real-time PCR assay for detection of Toxoplasma gondii in pig and mouse tissues. J Clin Microbiol 2001; 39: 2065-2071. 
19. Costa J-M, Pautas C, Ernault P, Foulet F, Cordonnier C, Bretagne S. Real-time PCR for diagnosis and follow-up of Toxoplasma reactivation after allogeneic stem cell transplantation using fluorescence resonance energy transfer hybridization probes. J Clin Microbiol 2000; 38: 2929-2932.

20. Pujol-Riqué M, Derouin F, García-Quintanilla A, Valls ME, Miró JM, Jiménez de Anta MT. Design of one-tube heminested PCR for detection of Toxoplasma gondii and comparison of three DNA purification methods. J Med Microbiol 1999; 48: $857-862$.

21. Hafid J, Sung RTM, Raberin H. Détection des antigènes circulants de Toxoplasma gondii par réaction d'immunoprécipitation dans la toxoplasmose murine. [Detection of circulating antigens of Toxoplasma gondii using immunoprecipitation reactions in murine toxoplasmosis.] Ann Soc Belg Med Trop 1989; 69: 49-56.

22. Godard I, Darcy F, Deslee D, Dessaint JP, Capron A. Isotypic profiles of antibody responses to Toxoplasma gondii infection in rats and mice: kinetic study and characterization of target antigens of immunoglobulin A antibodies. Infect Immun 1990; 58: $2446-2451$

23. Thapar M, Kumari GL, Shrivastav TG, Pandey PK. Hormonal control of implantation in guinea pigs. Steroids 1988; 52: 85108

24. Burg JL, Grover CM, Pouletty P, Boothroyd JC. Direct and sensitive detection of a pathogenic protozoan, Toxoplasma gondii, by polymerase chain reaction. J Clin Microbiol 1989; 27: $1787-1792$

25. Paugam A, Dupouy-Camet J, Sumuyen MH, Romand S, Lamoril J, Derouin F. Detection of Toxoplasma gondi parasitemia by polymerase chain reaction in perorally infected mice. Parasite 1995; 2: 181-184.

26. Giraud P, Payan H, Toga M, Berard M, Dubois D, Laugier M
Toxoplasmose congénitale aiguë expérimentale du cobaye. Corrélations cliniques, biologiques et anatomiques. [Experimental acute congenital toxoplasmosis in guinea pigs. Clinical, biologic and anatomical correlations.] Ann Anat Pathol 1965; 10: $337-350$.

27. Hafid J, Flori P, Raberin H, Tran Manh Sung R. Comparison of PCR, capture ELISA and immunoblotting for detection of Toxoplasma gondii in infected mice. J Med Microbiol 2001; 50: $1100-1104$.

28. Fricker-Hidalgo H, Pelloux H, Racinet $\mathrm{C}$ et al. Detection of Toxoplasma gondii in 94 placentae from infected women by polymerase chain reaction, in vivo, and in vitro cultures. Placenta 1998; 19: 545-549.

29. Pelloux H, Guy E, Angelici MC et al. A second European collaborative study on polymerase chain reaction for Toxoplasma gondii, involving 15 teams. FEMS Microbiol Lett 1998; 165: $231-237$

30. Khalifa KES, Roth A, Roth B, Arasteh KN, Janitschke K. Value of PCR for evaluating occurrence of parasitemia in immunocompromised patients with cerebral and extracerebral toxoplasmosis. J Clin Microbiol 1994; 32: 2813-2819.

31. Zenner L, Darcy F, Capron A, Cesbron-Delauw M-F. Toxoplasma gondii: kinetics of the dissemination in the host tissues during the acute phase of infection of mice and rats. Exp Parasitol 1998; 90: 86-94.

32. Costa JM, Ernault P, Gauthier E, Bretagne S. Prenatal diagnosis of congenital toxoplasmosis by duplex real-time PCR using fluorescence resonance energy transfer hybridation probes. Prenat Diagn 2001; 21: 85-88.

33. Luo W, Aosai F, Ueda M et al. Kinetics in parasite abundance in susceptible and resistant mice infected with an avirulent strain of Toxoplasma gondii by using quantitative competitive PCR. J Parasitol 1997; 83: 1070-1074. 